Discussion on Paper No. 6768*

\title{
Jig for the construction of a 17-storey block of flats at Barras Heath, Coventry
}

\author{
by
}

F. Adler, B.Sc., M.I.C.E.

\begin{abstract}
Mr P. Lederer (Managing Director, Richard Costain (Construction) Ltd) said that the experience of the Coventry jack-block was one that was probably common to many organizations which were trying to introduce innovations and improvements into the building industry. Apart from the technical problems and the interest which arose when attempting solutions to technical problems, there was a problem of organization. It might be anticipating a question if he said that the costs at Coventry were higher than the contract price. They were satisfied with the experience gained at Coventry, and with the lessons learned; but new ideas and improvements were not brought about easily, and one of the factors was the personal training which each member of a team, however organized that team might be, brought to bear on the problem. Each team member was still either an architect, with training concentrated on producing a building from the point of view of its ultimate use, or a structural, heating, or hydraulic engineer, or a quantity surveyor whose particular skills and training and experience tended to be based on the costs of components and of parts of buildings constructed by traditional methods. He believed there was a lot of work to be done in thinking out effective ways of integrating the contributions of these various very necessary team members in order to achieve the best result in terms of production cost as well as a satisfactory ultimate building. He wondered whether anyone would speak about methods used in bringing about this ultimate objective in turning ideas into economic reality.
\end{abstract}

Mr R. Bidgood (Senior Executive, British Lift Slab Ltd) congratulated the Author on his Paper and on his skill, ingenuity and courage in evolving the jack-block system of construction. He was particularly impressed by his refreshingly new philosophy of 'jig construction' and, as a member of an organization also concerned with constructing multi-storey buildings using a hydraulic jacking system giving vertical movement of both the jig itself and of jig formed components, he appreciated the Author's invitation to join the 'jig club'.

72. His organization's jig was based on the lift slab method of multi-storey construction together with a slip-form system of sliding formwork. It was in 1913 that a Chicago engineer, Peltzer, took out the first patent on a lift slab type of construction which employed manually operated screw jacks placed on top of each of the columns to lift the plate floors up the columns, which themselves were virtually being slipformed as jacking commenced. Unfortunately, the structural form of the plate slab frame was still then very much in its infancy and the patent was not exploited.

73. Since 1950, and in Great Britain since 1958, lift slab had become established as a principle and, if anything, was now stimulating the technique of the plate slab

* Proc. Instn civ. Engrs, vol. 27, March 1964, pp. 433-464. 
DISCUSSION ON JIG FOR THE CONSTRUCTION OF A

17-STOREY BLOCK OF FLATS AT BARRAS HEATH, COVENTRY
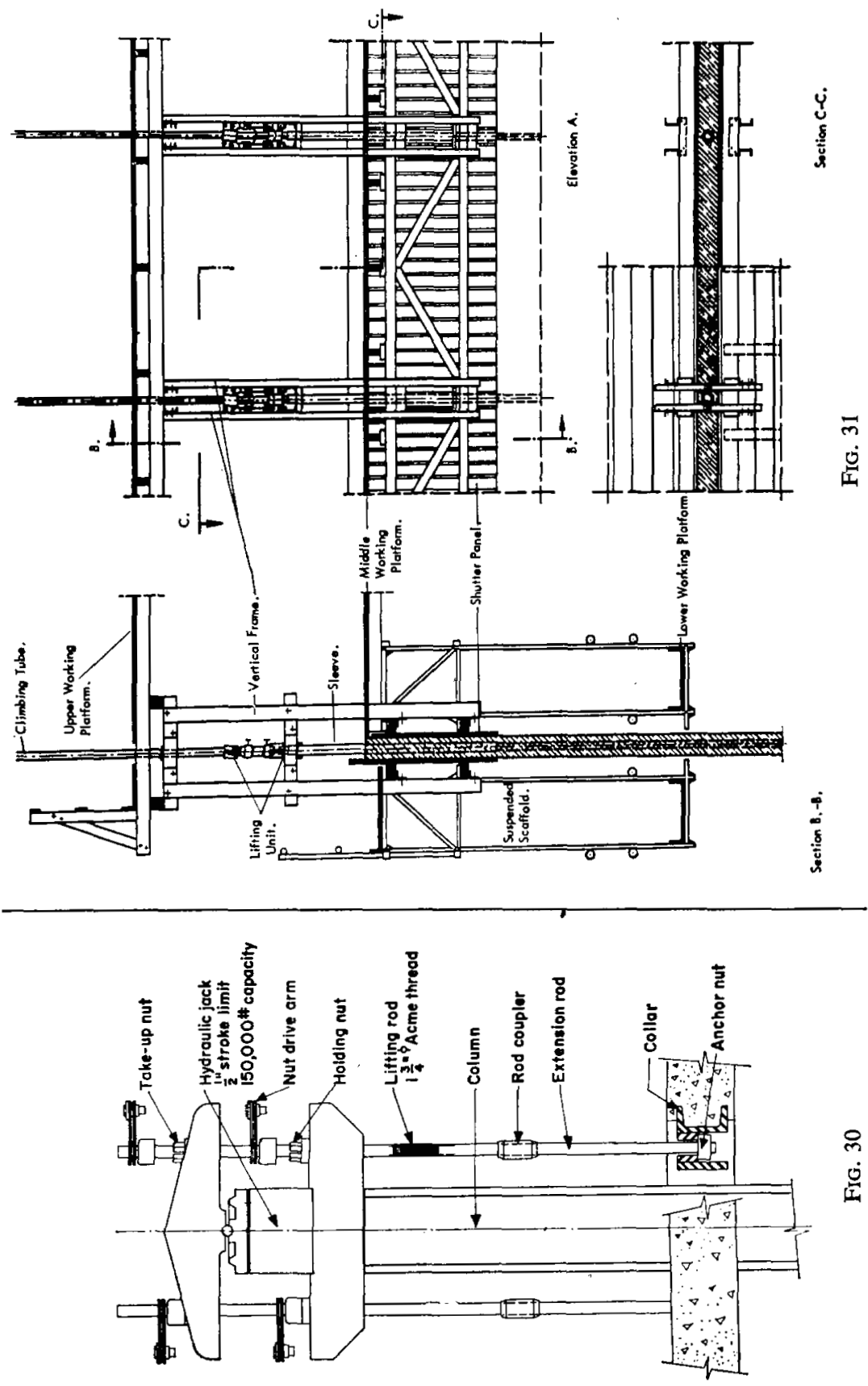


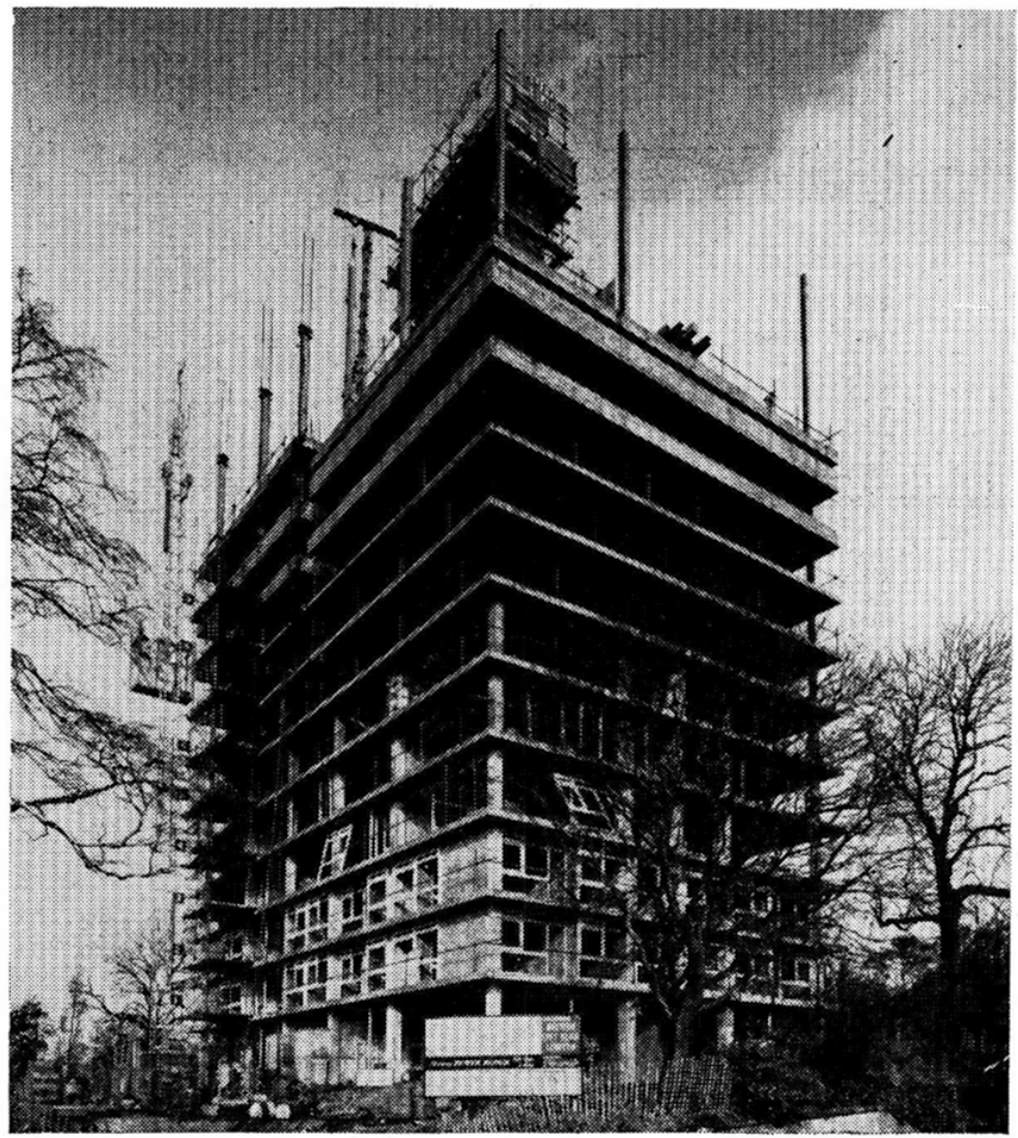

FIG. 32

'open' frame. But, whereas Mr Adler's system relied on the jacks pushing from underneath, lift slab relied on jacks pulling from on top of each of the columns. Fig. 30 showed the jacks and the method of attaching the lifting rods to any particular floor-slab or group of slabs.

74. The other element of the jig was the slip-form for core-shaft and shear wall construction, which could also be applied to the vertical elements of complete buildings in the case of suitable cross-wall structures. A section of this arrangement was shown in Fig. 31. The top platform was for the assembly of reinforcement, the middle for concreting and the insertion of inserts and components, and the lower platform for the removal of inserts and for finishing.

75. Fig. 31 also showed a pair of climbing jacks reacting on each of a number of 2 -in. tubes placed in sleeves (and later recovered), which allowed both vertical and a limited degree of horizontal movement, and also tapering and reducing sections to be formed.

76. It was by using both lift slab and slip-form principles in one integrated jig 


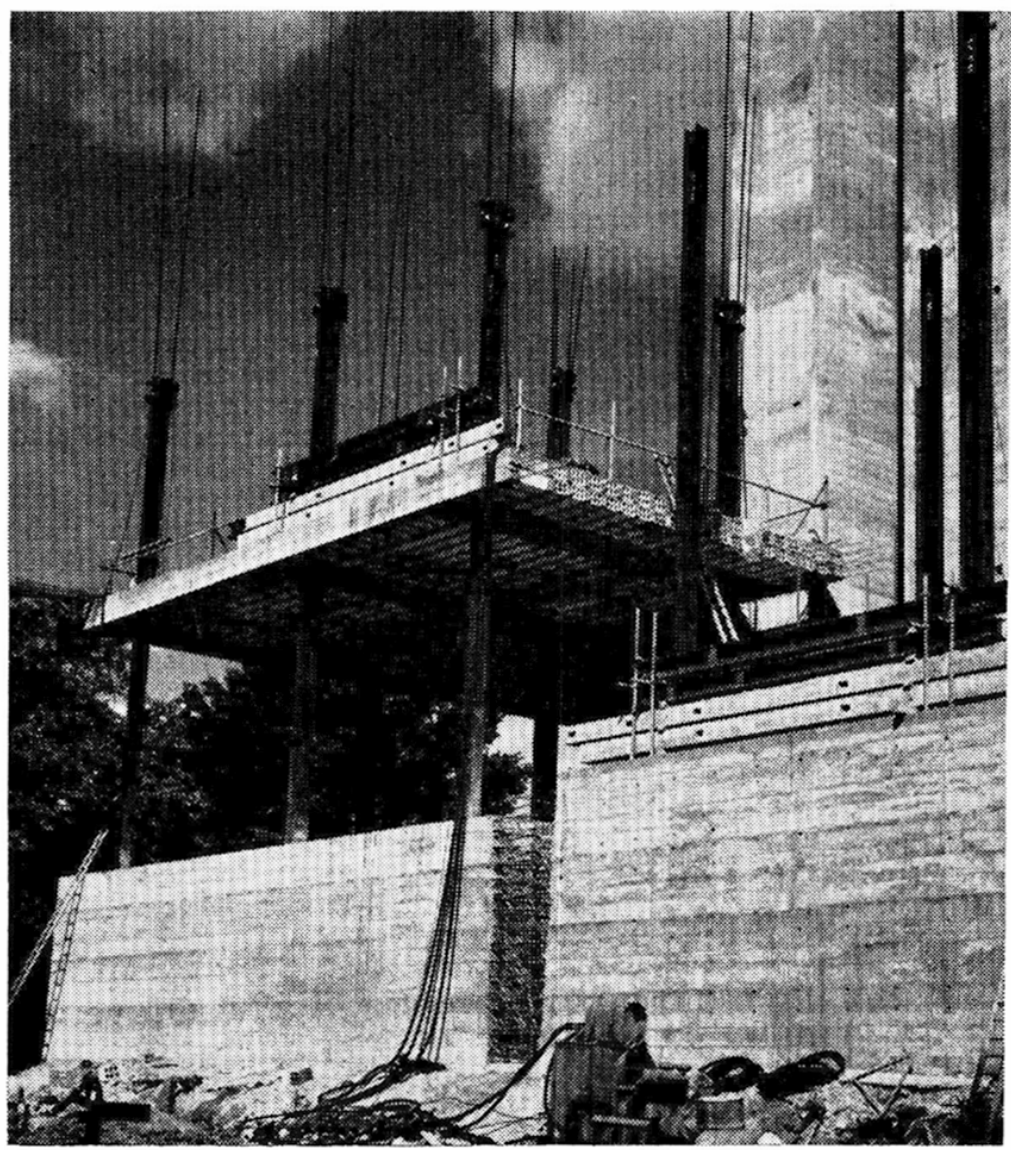

Fig. 33

that a 17-storey block of flats was constructed at Coventry. Fig. 32 showed the central core shaft slip-formed to its first stage with the slabs partially lifted.

77. Fig. 33 showed the two halves of the building with the slabs at ground level, ultimately joined together with an in-situ strip; on one side lifting would be undertaken while on the other side the columns would be extended. Initially, steel columns were used and later these were changed to reinforced concrete to maintain a constant cross section.

78. The processes of slipping and lifting proceeded virtually continuously, allowing the primary structural elements to be constructed apace. Slipping and lifting were of course structurally independent during their vertical travel but, when the processes were complete, they joined forces and gave one integrated structural unit.

Mr G. M. Rose (Consulting Civil and Structural Engineer) said that he would concentrate mainly on the factory aspect of the Paper. He had been privileged to 
work on that type of slab in Canada more than ten years previously. In that particular case in Calgary, during the normal very bad winter, all the slabs were poured in the basement under a temporary, heated cover and lifted in the spring. Perhaps this was one of the first factory-type buildings. His work on this slab had shown that many of the advantages claimed by the structural engineer for flat slab construction and swift methods in fact reflected in large proportion the advantages gained by forcing the architect to adopt a definite architectural shape and all the suppliers of plumbing and electrical services to be actually on the site for the finished job on the day that the contract started. He felt even now that if this spirit could be induced into normal building many of these advantages would be reflected there. Perhaps the Author would comment on the scale of effect this had on the speed of building and on whether, in fact, any ingenious finishing methods and servicing methods had any great influence. For example, the lift shaft must be rather unusual in a building of this sort, and it was normally rather difficult in practice to get lift manufacturers either to speed their supply or to produce the type which must have been required in the present instance. How did the Author's company fare in this respect?

80. Early in the lift slab days a number of large scale tests was done in the University of Toronto for some of the particular connexions that lift slab then required, with the knowledge of flat slab as it was then. Mr Rose felt that system building in Great Britain and, indeed, elsewhere must suffer from having to perform the type of large scale load test which Mr Adler described and which seldom, if ever, could be entertained on a normal contract from the price aspect.

81. He wondered if there was not some call now for, say, a committee or a jury of engineers, perhaps of this Institution, to which all system builders (and there were more every day) could submit their plans and their schemes. They could receive guidance as to whether the project really needed full scale testing or whether it had been accepted abroad before and could therefore be accepted here, or whether the analysis of the structural engineer could not be accepted outright. He was thinking in particular of the blocks of concrete which could have been analysed, perhaps, as well as tested. But even to this day the lift slab theories of unsupported columns in cantilever were not generally accepted, and it would be a good thing if there were some central body to authorize and recommend the procedure.

82. Mr Rose's idea of a site factory came with the suspended type of structure, and he felt that the cantilever core structure, while useful for suspension work in this type of jacking system, was in itself not the cheapest possible form for a square block. In a suspended structure he thought that two towers would give a better economy than one. In other words, it would be better to erect on one set of prepared foundations two towers, which could be done in sliding formwork and at a very fast rate, and actually bridged across at this high level. The bridging member could be conventional or new but should serve mainly to carry verticle cables which would be fixed temporarily to the ground. At this stage it could largely resemble Mr Adler's effort, in that individual concrete boxes consisting of, say, 4-in. wall and floor slabs, could be built at this level, raised to a higher level by jacks and then completed as far as their horizontal surfaces were concerned and pulled right to the top and finally fixed. Thus it was not necessary to lift the whole of the weight of a building, and there was some compromise between a lift slab which lifted only a floor at a time and a jackblock which lifted a complete building at a time. If the finished structure were then on a pair of supports, rather than a single cantilever column, greater economy would be achieved.

83. Mr Rose found that it was cheaper to build these types of structures with normal methods, than with any other system at present available. The only saving grace in the new system was therefore in the savings that were made by factory or jig methods over and above the cost of the structure. He wondered if $\mathrm{Mr}$ Adler felt that the savings of factory methods for finishings justified any otherwise unusual structure. If this were the case, he thought that in future the profession would be 
overwhelmed by a vast amount of novel structures and he felt that engineers ought to be better equipped than they now were to consider and adjudicate upon these methods.

84. In his concept of jig construction, therefore, $\mathrm{Mr}$ Adler advanced building technique much further along the road of mechanization than the emphasis on structural detail would suggest, and he was to be congratulated not only on this, but on having actually overcome the forces of prejudice which must have been just as great as the forces on the foundations.

Mr F. J. Hansen (Chief Engineer, Christiani and Nielson) said that he did not belong to the 'jig club' and he could not tell how one turned a good idea into an economic solution. He congratulated the Author on his Paper; he had shown that something which probably no one else would have dared to do could actually be done. It would no doubt open the door for many new and exciting projects.

86. It seemed very daring to have such a tall building standing on a cushion of oil and one could not help feeling that it might topple over. However, was it not, in a way, easier to make a jack-block house plumb than an ordinary house? For with the ordinary house one had to be a very good soil mechanic to predict the settlement of the ground, whereas with the jack-block, apparently, if the ground happened to settle more in one corner than another, it could be remedied at any time during construction. Hydraulics was, of course, the answer to several problems, as the Author had pointed out, and Mr Hansen had used it himself a couple of times. Figs 34 and 35 illustrated this work.

87. Fig. 34 showed a bridge with eleven spans in all. It was fixed at the two ends and there was an expansion joint in the middle, so that there were six and five spans where the expansion took place. The columns were fully fixed into the superstructure so that all movement of the superstructure caused bending in the columns. The superstructure was a prestressed, fully in-situ construction. The columns had to be very slender to accommodate the movements but they were also so heavily loaded that no stresses from built-in moments from the construction were permitted. The temperature in the final structure would produce stresses just to the limit. It was therefore specified that the columns be vertically loaded with no bending at the end of the construction. That posed a number of problems, since shrinkage, creep, and elastic shortening due to stressing of five spans would cause considerable shortening and therefore bending moments in the columns. To avoid that the bridge had to be constructed the other way round, from superstructure to foundation, i.e. the deck was finished before it was tied to the column, and thus caused no bending moments. The deck therefore had to be supported in three entirely different ways. Firstly, while concreting the whole area of a bay $85 \mathrm{ft}$ long and $100 \mathrm{ft}$ wide, all the weight had to be carried as a uniform load; thereafter when prestressed, the whole span would throw the weight to the two ends, so that the whole load of 1000 tons per span then had to be carried on two line supports. When the cross beam had been cast and jointed to the columns, the total load finally had to be transmitted to the

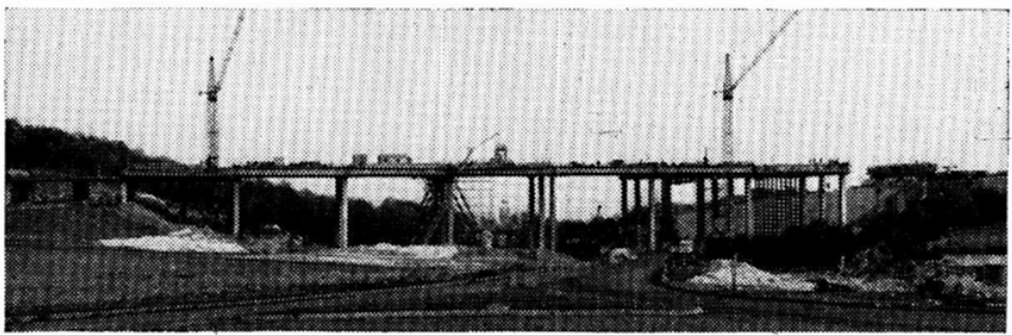

FIG. 34 


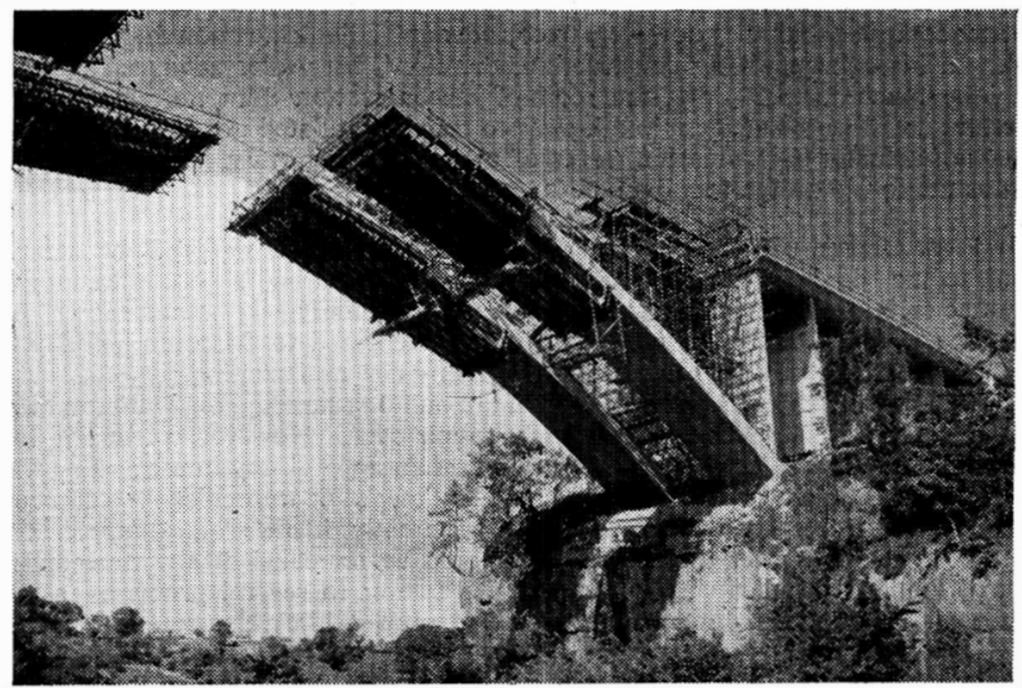

FIG. 35

three columns. As soon as the concrete had been cast the whole superstructure was rigid, so that the whole load transference from one system to another had to take place without elastic deformation. It was impossible in practice to produce a supporting system $80 \mathrm{ft}$ high and $100 \mathrm{ft}$ wide with no appreciable elastic deformations, while throwing 1000 tons load on to the two ends. The only solution was to have hydraulic jacks at all supporting points controlling the loads and thereby the deflexions of the structure, since only a slight deformation would have caused complete redistribution of the forces and stresses in the span.

88. Fig. 36 was another example of jacks being used for the construction of an arch. It was a fully fixed arch which was cantilevered out from the abutments with no supports to the ground, but with suspension cables taken back to the abitments over the top of the bridge. Without prestressing it was inadequate, since the stretch of the cables would have been too much for the arch to follow, whereas by means of hydraulic jacks and prestressing, the stresses in the arch were easily controlled. The whole problem was reduced to that of controlling the level of the bridge. The arch was so flexible that simply by observing it with an instrument one could predict the stresses to within a few pounds per square inch.

89. In several instances in France, buildings had had to be moved when they were in the path of a motorway, for example. That was a very different proposition, however. The whole jack-block building was designed for that type of process, whereas a 400-year-old brick mansion most certainly was not meant to be moved. To jack $\mathrm{s}$ uch a building up and roll it half a mile up the road required extraordinary control. No relative movements within the structure were permissible when travelling over r ough ground. It could be done hydraulically, however, without pulling the building down.

Mr A. C. Hughes (Principal Civil and Structural Engineer, Coventry Corporation), in congratulating the Author on his Paper and on the successful completion of a really major project, said that Coventry Corporation and its officers were keen to try new and good ideas, and had been pleased to collaborate with the Author and his firm in 
the development and erection of the 17-storey block. Mr Adler, in his unassuming way, did not really do justice to this invention when he said that a "satisfactory answer to the problem' had been found. It was the first multi-storey building in the world to be constructed by this method, and it was the most important engineering feat of the year. Throughout the whole of the design and the construction periods there had been the closest co-operation with the City Engineer's Department in Coventry, and it was very pleasant to be able to say that structural and safety needs were never at any time subservient to contractual needs, whether they were physical or financial. At no time were the investigations requested by the department too much trouble for the Author's firm to carry out either by calculation or experiment.

91. A major advantage of the jack-block method was that one worked with lighter loads above in the early operations, and the firm had taken advantage of this. For example, a small number of jacks had been tried out in the first place, lifting at rather higher pressures than was necessary initially, in order to try the effect of the ultimate heavy loads to be experienced in the later stages. With regard to the concrete used in casting the large base slab where not very high strength was required, the firm took advantage of the situation to use various mixes of a much higher quality in order to obtain satisfactory mixes for the later floor slabs which would be much more complicated and more highly stressed. The kind of figures obtained were, for example, $6000 \mathrm{lb} / \mathrm{sq}$. in. at transfer and $8000 \mathrm{lb} / \mathrm{sq}$. in. at 28 days, and the coefficient of variation was only about $\pm 6 \%$ on the mean strength, which was a very good degree of control, and had been obtained throughout the whole job.

92. The Author had referred to the possible reduction in the lifting cycle from 14 to 7 days. Did he consider that this would be realistic for the various finishing trades that would have to follow? If so, would the test results on the various stacks of cold blocks enable him to cast each storey height in two operations only instead of the three which were used on the job?

93. Could the Author also give some indication of the economics of the method compared with conventional bottom-to-top building, because this method offered so many constructional advantages that it would be encouraging to know that it would be economical on future buildings.

Mr I. Reith (formerly Engineer Agent, Richard Costain (Construction) Ltd) in adding his congratulations on an excellent Paper, said that there were two intriguing possibilities which were worth mentioning as far as jack-block technique was concerned. The first was the possibility of building extensions to multi-storey buildings by what he would call an 'under-building' process. This might well be a necessary part of the later twentieth century building programme where speed of building and density would possibly have to increase beyond all present calculations. He felt that the technique could be employed to increase the height of, say, a 20-storey block of flats, offices or a hospital, to, say, 30 storeys, without causing too much inconvenience to the tenants or occupants. Certain problems would have to be overcome in terms of temporary services, etc, but there were considerable advantages in 'underbuilding' rather than 'over-building' or producing an extension on top of an existing structure where the building was kept in occupation during this period.

95. The other possibility was the use of the technique in mining subsidence areas. The height of buildings is at present severely restricted in such areas and the technique produced a structure sufficiently strong and rigid to withstand the various stresses induced by settlement. It also allowed the building to be re-aligned easily to vertical plumb should tilt take place.

96. Experience at Coventry had shown that there was no distress whatsoever to finishes as a result of correcting tilt equivalent to $1 \mathrm{ft}$ in a height of $180 \mathrm{ft}$. He was quite sure that it was possible to go well beyond this figure without causing distress to sensitive finishes of the type employed at Coventry.

97. It was important that one should differentiate between a jig for a structure 
and one for structure and finishes. Jack-block was undoubtedly a jig of the latter type. The advantages of the technique were entirely lost unless supplies for the finishing trades were brought into that programme. As a matter of routine at Coventry sufficient supplies were held on site for structure and finishes for a period of two weeks: in other words, sufficient material was held in reserve on site to construct one floor. That proved advantageous, of course, during the cold spell at the beginning of 1963. The only supplies which caused a certain amount of embarrassment were coarse aggregates due to the freezing up of the washing and screening plant at the pits. Fortunately, owing to the specification requirements for the grading of coarse aggregates, stock piles had been formed at the pits and it was therefore only necessary to dig out the frozen aggregates, transport them by lorry and de-freeze on site. The important point arising from this was that the only way in which to get supplies on time, on programme, was to build up confidence between the supplier and the contractor on site. The jack-block technique undoubtedly allowed suppliers to programme many months ahead and to deliver virtually to the day, according to the master programme, and therefore considerable confidence was built up between supplier and contractor. This he felt, was one of the most important assets of the integrated jig.

98. Apart from the many problems of building upside down by this technique (lift engineers, plumbers, and various other conventional trades had to work in reverse order), they were also faced with the unforeseen problem of whether to have a topping-out or a bottoming-up ceremony. The former was chosen, and he believed that the master programme suffered in consequence.

Mr G. Wimborne (Ronald Ward \& Partners), speaking on behalf of his firm as architects, thanked the Institution for the invitation to contribute to the discussion. He had had some personal experience of a tall building on the Millbank development.

100. Mr Adler's ideal of jacking a complete building possibly some 30 to 40 floors in height for its full height was bold and fascinating, and in itself inspiring to all interested in advancing building technology. The system required that the building be finalized in all essentials well in advance of construction, and once these were settled no alterations must be made. This was an extremely important factor, but it also presented all concerned with serious limitations.

101. In practice, a tall building, particularly for occupation by an owner-occupier, might be subject to many vicissitudes during erection, in spite of much preplanning, and sometimes for quite unforeseen reasons. For instance, a company merger might take place before construction was complete.

102. Accepting for the purpose of this discussion that a standardized form of building such as a block of flats lent itself to system building, he would attempt a brief assessment of the stages prior to the erection of most tall prestige office buildings. Usually a tall building was subject to very careful consideration by the authorities, particularly with regard to planning. Quite often the design was referred to the Royal Fine Arts Commission for comment, and public inquiry might also arise before consent could be obtained. These factors could mean that a year or two would elapse before the shape of the building could be determined in its final form.

103. For the very reason that the planning stage might involve changes in design, final plans might not be practical except in a broad and exploratory sense during this period. Assuming that planning consent was obtained, by-law and Building Act requirements must be established and complied with and statutory undertakings consulted. When this stage was reached a period of very closely co-ordinated planning and cost assessment was required. Close liaison between the architect, the structural consultants, the mechanical consultants, quantity surveyors, and others would finally determine the main elements of the building. This stage was extremely important in most buildings and was particularly important and time-consuming in the case of a tall building. Quite often decisions might not be possible on, say, the 


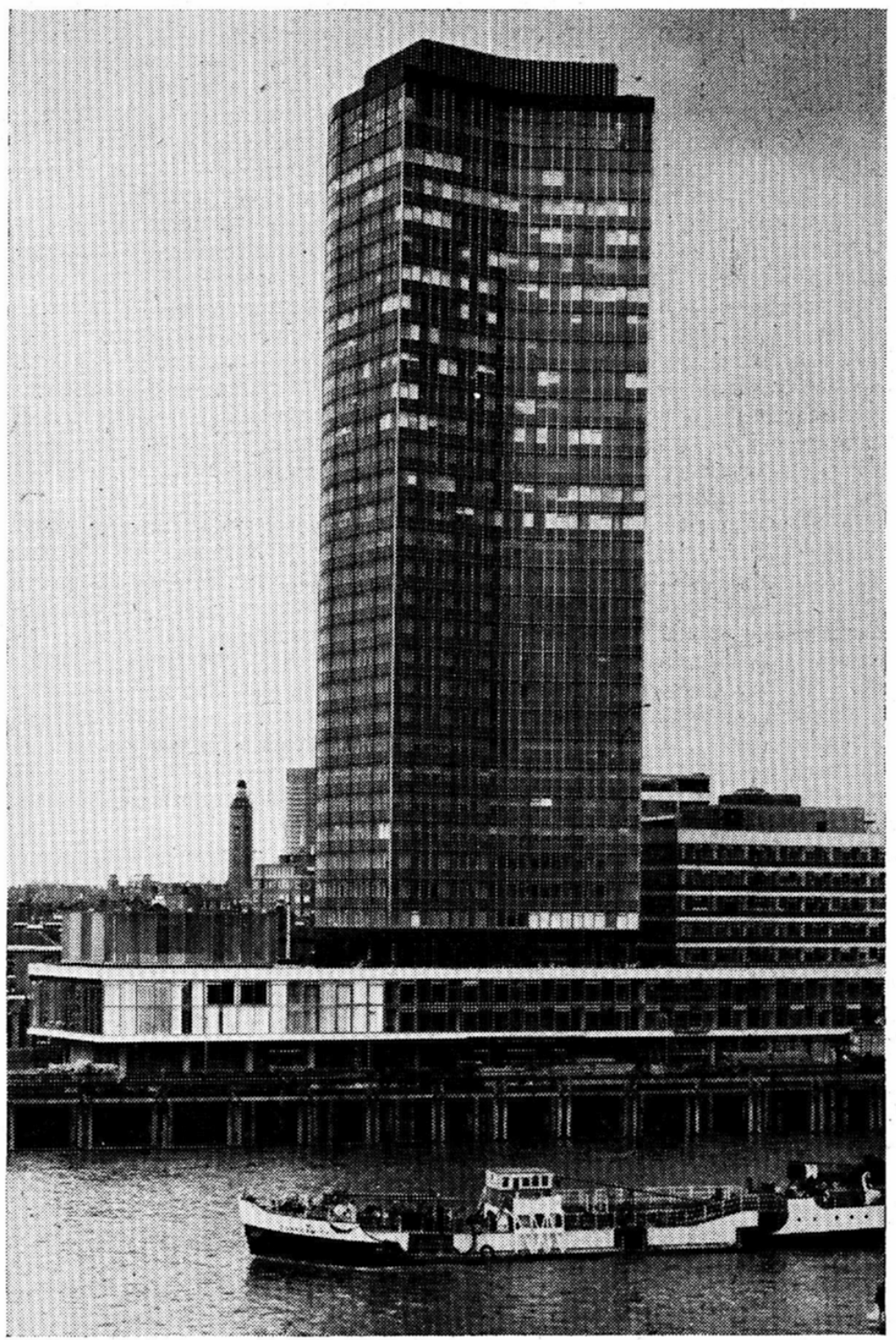

FIG. 36

air-conditioning system and other mechanical service systems, and before a good deal of the design work had been completed tenders might have to be obtained for quite detailed mechanical services installation. While waiting for these to come in and making all the necessary financial decisions, as well as the technical ones, time 
passed. If the design were then to be translated into a form of system building, much more time and detailed and advanced planning must be undertaken in advance of construction. This was quite apart from standard details and other items which would in any case have to be dealt with, as in the majority of buildings. The difficulties which then arose seemed to revolve around such items as restaurants, directors' suites, social amenities, and the very many other things which probably the client would then decide were necessary or which his organizational requirements might demand, and all this had to be done well in advance of construction.

104. A further point arose on the question of cost. If the client were not to be denied the benefit of at least limited competition, a form of construction enabling this to be obtained might be considered desirable. If in the early stages of the design it were to be assumed that a particular system such as jack-block were to be used, this would limit the choice to the licensees of the system. It might be argued that in these days of negotiated tenders such an arrangement was not unreasonable, but it could equally well be argued that the decision to use a particular system must be taken at too early a stage of the design of the building to enable all the design features to comply with the system. In practice, and from the client's point of view, a very considerable saving would have to be shown to be obtainable, to justify the initial decision in favour of any particular system.

105. He did not feel at present that the use of such a system on a tall prestige building would show an overall saving in the time taken, from the initial instructions to the architect to the completion of the finished building. It did show that provided all the details were settled well in advance of work commencing on site, a saving in time and labour should result in terms of actual site operations, and that was really the main point emerging from the discussion.

106. On the question of speed alone, some quite outstanding achievements had been obtained using more conventional forms of construction, probably with a much larger labour force. He was, however, a little sceptical, assuming the jack-block system were used, that in practice one would be jacking a completed floor in every sense of the word at say, the rate of one per week on a building of something in the region of 12000 to $15000 \mathrm{sq}$. $\mathrm{ft}$ of floor space per floor.

107. Fig. 36 showed the finished building, to illustrate the question of size, because in the case of Coventry they had been talking about a building of approximately $2500 \mathrm{sq}$. $\mathrm{ft}$ in area. It was more likely that while a good deal of the main structure of the building and possibly enclosures would be completed in the time, the physical restrictions of assembling all the sub-trades on, say, the lower two or three floors of the building, to enable all these operations to be completed, might have considerable drawbacks. It was conceivable that as the building grew in height, more and more men would still be required to be working at different heights within the building, and they would in turn require the various services to enable them to function-lifts, canteens, tea stations, lavatories, and power, and the many other things which a contractor had to provide. In addition, as the services were installed, many would possibly have to be reconnected each time the building was jacked up.

108. Quite often in the U.S.A., and now to a certain extent in Great Britain, consideration was being given to occupying the first ten floors of a 30 - or 40-storey building while work continued on the upper floors, thus giving phased occupation to the tenants or occupiers. In practice, one could not conceive that this sort of idea would work out where the building was being jacked up. No doubt the short answer would be that the building went up so quickly that there would not be much advantage in installing the occupants during the course of construction. This would have to be demonstrated in practice on a working example to prove the point.

109. Mr Wimborne realized that, in dealing with a particular type of building, his statements might have only limited value, but he had simply attempted to demonstrate what would appear to be some of the snags in applying new techniques in certain instances. 
110. It was quite possible that prefabrication could slow down a job, and they had found that in dealing with certain standardized components of building which were designed for a particular project, but mass-produced in the factory, production snags and delivery problems did in fact mean a delay, which would not have arisen where more conventional and traditional methods were employed.

111. In addition, if a particular requirement or perhaps the non-acceptance of a particular design feature by the client arose, the more conventional methods still allowed greater flexibility in meeting these situations.

112. System building had an increasing part to play in the future, particularly where it could be applied to problems of urban renewal, such as large-scale rehousing, and where the site time was of fundamental importance in enabling the decanting and re-housing of the population to be carried out. At the moment there seemed to be two schools of thought on system building. On the one hand there was the principle that the components were made in a factory and transported some miles to the site where they were assembled; on the other hand there was the site factory, whereby the system or building was pre-fabricated in some form and erected within the site. There were obvious advantages and disadvantages with both, and no doubt time would tell which of the two principal systems was likely to produce the majority of the standardized buildings of the future.

113. In conclusion, he wished to mention one point in the jack-block system which at present seemed to be slowing the process down. This was the time taken to stress and cast the floors. There would seem to be some advantage in the suggestion made by $\mathrm{Mr}$ Adler that a form of suspended perimeter framing be dropped down from the top of the building, and this in turn could be used to pick up the floor slab, which might have to be precast.

Mr R. S. Jenkins (Partner, Ove Arup \& Partners) said that the Paper described in a very convincing way the many advantages of building a tall block in reverse. The

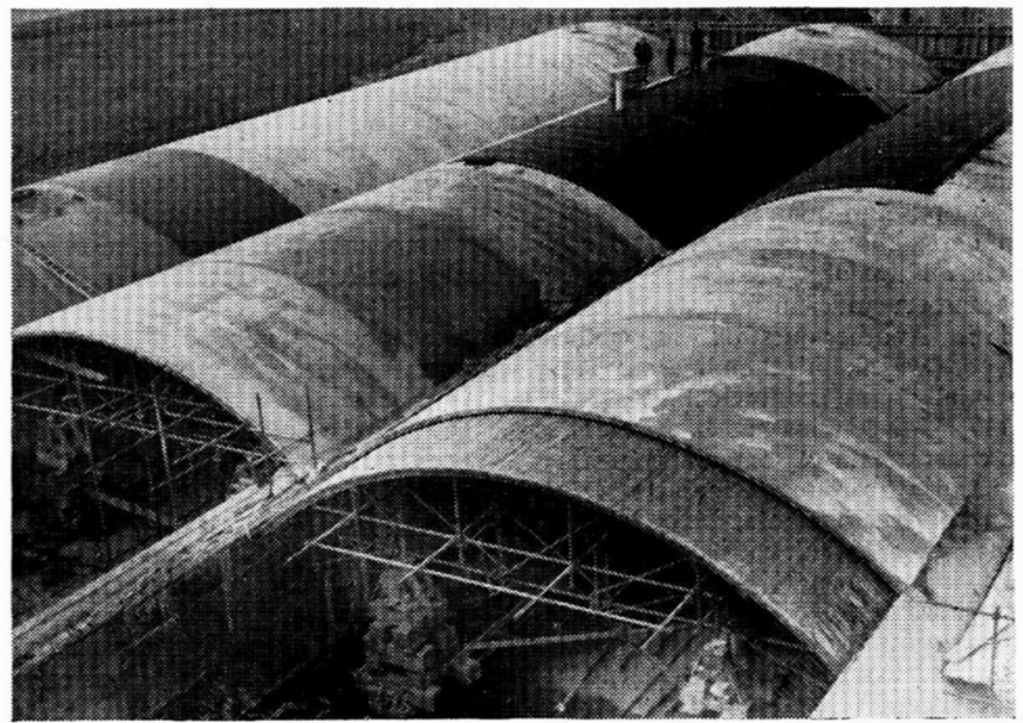

Fig. 37: R.A.F. HANGaR, AbINGdon: THE three SHElls to No. 1 HaNGaR RoOF 


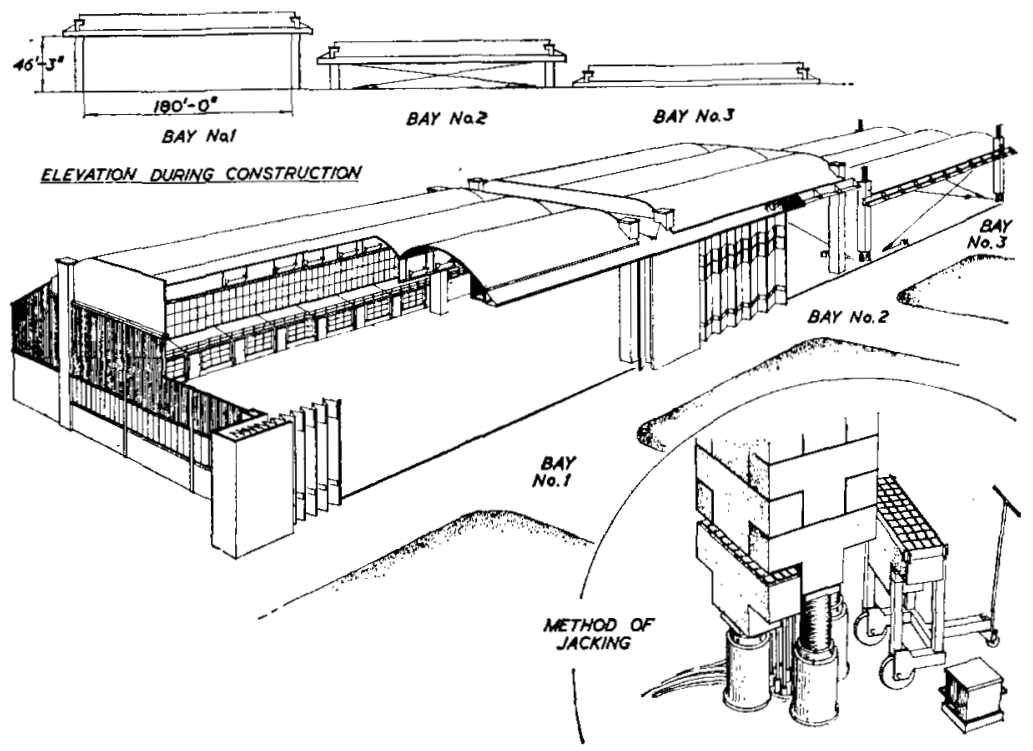

Fig. 38: Perspective view OF THREe-Bay haNGar

method of making the structure had worked brilliantly because Mr Adler had squarely faced all the practical difficulties and had shown great ingenuity in overcoming them. The better working conditions for all the other work which in cost had amounted to $75-80 \%$ of the total, was also an increasingly important aspect. Notwithstanding the advantages in speed of construction and working conditions, $\mathrm{Mr}$ Jenkins thought that this and other methods of industrialized building, when used on a necessarily large scale, would have to be competitive in cost with traditional methods.

115. The important question was therefore not the cost of this prototype, but what in the light of this experience would be the cost assessment for future production of an optimum quantity of blocks of this type. He would like the Author to say something about this question. He wished to emphasize that for the nation to reap the advantage of systems such as this, it would be necessary for some authority to guarantee a sufficient number of repeats.

116. Another question was whether the point block with floors cantilevering from the core was the ideal embodiment or whether slab blocks with crosswalls would be essentially more economical.

117. Mr Jenkins had had experience of another type of jackblock technique in the construction of some hangers which his firm had developed with John Laing \& Son Ltd, who were the builders. Although the Abingdon work was much simpler than constructing point blocks, it illustrated some of the essential features. The three bays of cylindrical shells for these hangers were built on the ground using simple travelling formwork (as shown in Fig. 37), which after travelling the length of one hanger went straight on into the next. The reason for the great economy of this construction was basically due to the extreme reduction of formwork and scaffolding compared with building these shells in the air. The cylindrical shape was essential to the idea.

118. Fig. 38 showed the method of jacking and introducing the column blocks. Instead of the dry joints used at Coventry, mortar joints were used at Abingdon, 


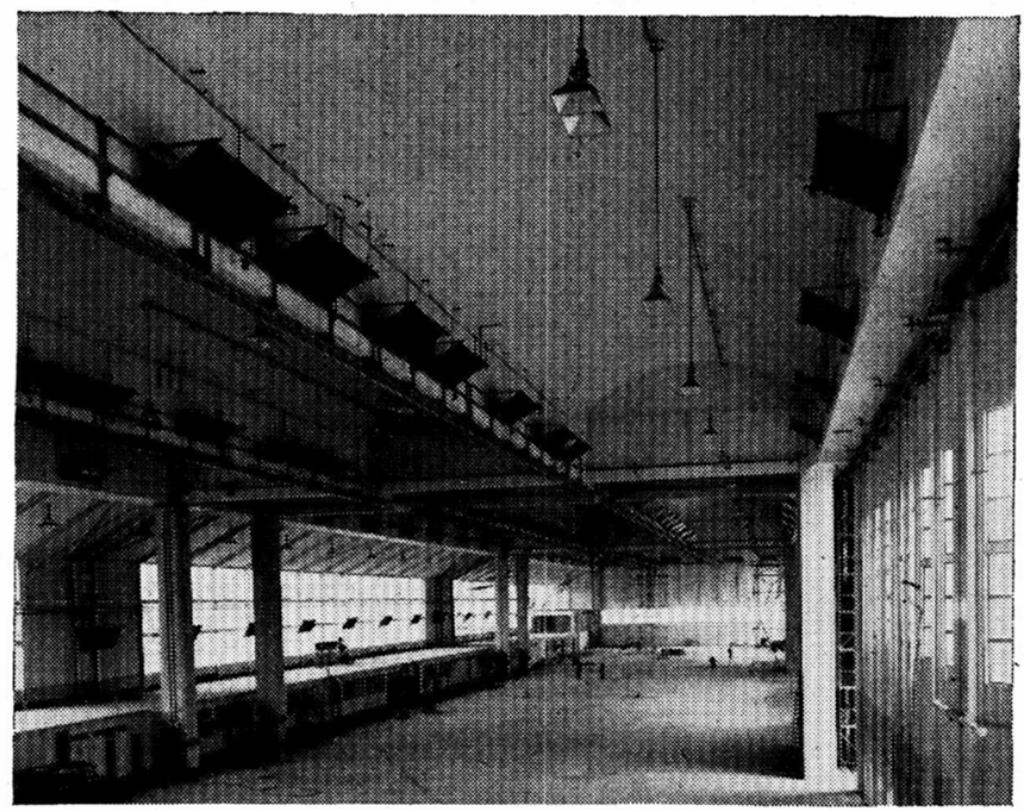

FIG. 39: INTERNAL VIEW OF HANGAR

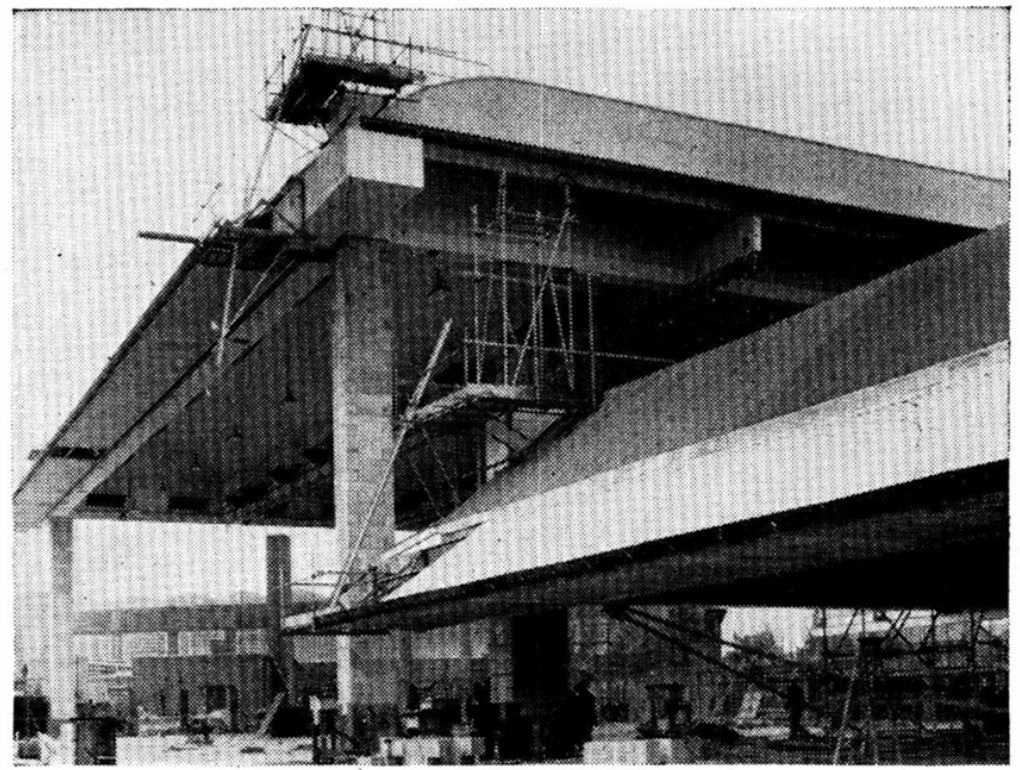

Fig. 40: PART OF No. 1 ROOF FUlly RAISED AND NO. 2 ROOF IN COURSE OF ERECTION 
where it was found that if the mortar beds were grooved to allow excess water to escape, the mortar joint could take its full load immediately. Fig. 38 showed this aspect and the fact that two jacks only were holding on fresh mortar beds when the other two were being retracted for the introduction of a further pair of blocks.

119. Another point which was also borne out by the Paper concerned all the work that could be done at fixed levels. At Abingdon insulating boards and roofing felt were on the upper surface, and inside was a mass of conduits, lights, and heating panels, and also joists for the rails of travelling gantry cranes which travelled the whole length of the three hangers, shown in Fig. 39. All these, as well as subsidiary structures, such as folding door canopies and for filling the gaps between hangers, were done at or near ground level. Fig. 40 showed one hanger fully raised and the jacks moved on to raising the next hanger.

120. There were four columns per hanger. They might appear rather small for the 180-ft clear span structures. Actually, their main function was to take wind loads and temperature changes because most of the shrinkage and creep of the prestressed shells could not be assumed to have taken place before the structure was raised to full height.

121. He had not mentioned load carrying because the weight of the structure was not nearly enough. The actual load in the columns was increased by approximately $100 \%$ by prestressing vertically through the hollow cores left by the blocks. Wind speeds and temperature changes were specified but the amount of vertical prestress was naturally arbitrary. It was fixed to make approximately the optimum size of columns.

122. During lifting and before the vertical column prestress had been carried out, the wind resistance of the structure was obviously limited. For this reason, as shown in Fig. 38, temporary wind bracing was introduced. This was normally kept slack but if high winds were expected it was tightened up to the same extent both ways by using extensometers.

Mr S. A. Findlay (General Manager, Scottish Special Housing Association), referring to the Scottish Special Housing Association which operated entirely in Scotland, said that it was a Government body whose task, inter alia, was to develop new techniques of building and to contract for new ideas such as jack-block, which accounted for his interest in the Paper. The Association's officers had travelled extensively in many of the Continental countries and visited British firms during the past ten years to gain ideas, some of which were now being tried out.

124. The techniques described in the Paper had not been tried, although they had been studied, since it was felt that the important point in building flats was simplicity of design. They were fairly standard in plan and building-trade labour was used to a large extent. These techniques could involve retraining and the less one had to depart from the more conventional erection sequence the better, although extensive mechanization could be introduced and in fact that had been done. The Association also had to bear in mind the economics of the building, as did local authorities, who were probably the chief clients for this kind of work. Speed was also important and in the present instance seemed to be reasonably satisfactory. No doubt it would improve as experience was gained. The Association considered that nowadays a speed of about seven days or less a floor was acceptable, but the whole process was largely financial, being related to a very large building programme which most people agreed had a high priority. The economics were vitally important to the local authority who had to recoup themselves as far as they could by rents, having regard to the subsidies received from the Government. It was therefore very important for them to obtain competitive and reasonable prices.

125. He was aware that it was very difficult to give costs of a prototype but any indication of costs in future contracts would be of interest. 
126. The architectural form was also important. The Association had a team of architects, structural engineers, electrical engineers, etc, working with the guidance of quantity surveyors on projects, many of which were on large sites of up to 2000 dwellings, where multi-storey blocks of flats of 26 storeys or less were built among lower dwellings, e.g. maisonettes. Systems were emerging which could deal with all the types and the cost of multi-storeys could be offset to some extent by lower dwellings on one particular project which was an economic unit. Was there any possibility of this particular system, or something similar, being incorporated for lower dwellings of, say, four to eight storeys, which might make the whole scheme rather more viable?

127. Mr Findlay specifically wished to know whether there were any indications of cost trends. What 'self' finishes could be incorporated? Some of the Continental and English systems gave a completely finished slab which formed one wall, and the window frames were ready glazed to receive it. Only the papering needed to be done. There was a variety of external finishes which were incorporated in the mould and were already part of the slab when it arrived on the site and was put into position. This was found to be of great help and dwellings could be occupied very quickly.

128. However, few could offer much architectural variation; they had a standard plain form. It was possible to adopt their system to one's own plan but that could raise the price. It would be interesting to know to what extent the Author's scheme could be flexible without undue increase in price.

129. Mr Findlay had noticed that the Author used high-alumina cement and was presumably satisfied with it. One paper presented previously ${ }^{1}$ appeared to contain several authenticated cases showing that because of the very high temperatures induced in the early stages there was a serious loss of strength over a comparatively short period.

Mr D. Smollett (Consulting Engineer) pointed out that a building of this nature used up a vast number of high-class technical man-hours. Fewer people might be working on the site but in his experience the type of labour used on a building site was more easily obtained and trained than the highly experienced and technical man who had to work out the details in the office. Construction of buildings of this type reduced the number of highly qualified technical men available and this could become a national problem unless, with possible increased building of the type in the future, it became possible to standardize on a vast scale. The 'one-off' might possibly pay financially, though he doubted that, but it would not pay on a technical balance level; it would use limited labour on site but a large amount of technical labour in the drawing office.

131. He had thought of the amount of pleasure Mr Adler and his associates must have had in the project. A large sum of money was placed at their disposal and he understood they had not had to show a profit. He was sure they enjoyed themselves in dealing with problems as they encountered them and in overcoming the difficulties.

132. This form of construction forced the specialists, such as lift manufacturers, to come to site in time. The whole job must have been settled in detail long before the first jig was positioned.

133. Mr Smollett had had numerous difficulties in obtaining the lift details in time and in installing them in time, even if the building was erected in the conventional manner. To obtain lifts on site at this very early stage and to install lift machinery so that it was actually in working order by the time the building was up must have been quite an undertaking.

Mr D. N. Mitchell (John Laing \& Son, Ltd) asked whether it was really necessary to have the central core and the long expensive cantilever floor slabs with this system. He emphasized the question put by Mr Jenkins earlier. Were cantilever floor slabs specified by the architect? In other words, did the architect conceive the idea of a 
block of flats and asked for tenders to build the design? Did the Author's firm say they could build it in jack-block or did they offer to build it in jack-block and suggest a central core? It seemed to him that the system would be more economic without long cantilevered floor slabs, provided there was a reasonably symmetrical arrangement of the jacks.

135. He believed that structural engineers must always tell the client or the architect when economy could be achieved by alteration to clients' or architects' plans, and in this particular case it would have been right to tell the architect that the design could be built but that the long span floors would be expensive whatever method was used.

136. With regard to the economics, Mr Mitchell suggested that the cost of the project would only emerge after it had been repeated several times. The key to economy was surely careful planning, careful design, ingenuity, co-ordination of design and construction, and above all, repetition.

\section{The following contributions were received in writing:}

Mr A. L. Benjamin (Civil Engineer, G. Maunsell \& Partners) wrote that the overriding virtue of the jack-block method of construction, as so excellently described in Mr Adler's Paper, was that the finishing operations could proceed simultaneously with the major part of the structural work. The finishing trades, moreover, could work in almost ideal conditions, namely, from the top of the structure downwards, as compared with the difficulty encountered in this respect in conventional and some other novel methods of constructing tall buildings. Attempts had of course been made in tall buildings to provide a weatherproof membrane at some intermediate level during the construction, to permit the finishing trades to work at the lower levels, whilst the structure was still being erected above. But the provision of such a layer was by no means easy or cheap and not always completely effective. In his opinion this was the oustanding virtue of the method of construction described. Would the Author say what period elapsed between the completion of the parking of the structure on the foundation and the absolute completion of the building ready for full occupation? As the main structure was apparently constructed at about the normal speed for other more usual methods of construction, possible earlier occupation was the point of interest and financial concern to potential clients.

138. Mr Benjamin sought information on some other points not referred to in the Paper. In his experience the use of prestressing within buildings usually gave rise to a number of problems in connexion with the effect of creep, greater elastic deflexion, etc. The building appeared to be clad externally with a lightweight cladding system. Were any special precautions considered necessary in the design and fixing of the cladding on the end of the comparatively long prestressed concrete beams, to take account of any possible exceptional differential movements, between one floor and the next? Such movement would tend to distort the cladding and possibly crack glazing or any other brittle materials used. Careful detailing would undoubtedly overcome this problem, if there was one, but doubtless at some additional cost.

139. Had any trouble been encountered with the finishes on the main core walls, built up of a large number of dry bedded blocks? Would Mr Adler say if plaster were used for the finishing of these walls, and if so what type, and had any exceptional cracking occurred either during jacking or subsequently?

140. What type of precast concrete floor unit was used to infill between the prestressed concrete cantilever beams and how had the floor screeds and finishes withstood the movement of the building during erection and afterwards?

141. If Mr Adler could give further information on the speed of completion of the building and on the presence or otherwise of the secondary structural effects, $\mathrm{Mr}$ Benjamin felt it would be of great interest to many. 
Mr N. Rayman (Deputy City Engineer \& Surveyor, Coventry) wrote that he was concerned in the initial feasibility studies and engineering appraisal of the jack-block method which led to the decision of Coventry Corporation to proceed with the Barras Heath block and was associated with the project during its construction.

143. At the present time the application of engineering techniques to building construction was being widely discussed as a means of speeding the production of buildings and reducing their costs. 'Industrialized' and system building methods were being propounded in profusion and the assessment of relative advantages of one or other of these methods was becoming increasingly complex and difficult. One of the constraints on the solution of building problems by system building was often the lack of flexibility of the system in adaptation to individual circumstances. Another might be the lack of scale of the project to give sufficient production run to bring costs down to the levels hoped for. In these circumstances the type of system building which is based on the production of conventional buildings in an unorthodox manner was probably more capable of avoiding the constraints mentioned than the industrialized type of building to which we were becoming accustomed. Of the former type of building, jack-block was one of the most interesting in its employment of proven civil engineering techniques in an unconventional manner.

144. No doubt contributors would advocate other concepts and methods of construction analogous with jack-block and their relative merits and demerits would be evaluated. It was not his intention to make comparisons but to comment on actual experience of jack-block construction. In this context Richard Costain (Construction) Ltd and all their staff connected with the Barras Heath project were to be complimented on the quality of the structural work that was achieved and the accuracy of their control of the building during the jacking operations. Mr Adler indicated in his Paper the ingenuity which was brought to bear in unforeseen circumstances to overcome difficult problems. Examination of Fig. 22 revealed an indication of the accuracy of construction control which was more than comparable with the accuracy of a conventionally constructed structure of similar form and size.

145. In connexion with this accuracy of control, the Author briefly referred in $\$ 12$ of the Paper to the advantages of the system in mining areas and it would be interesting to know whether there had been any developments of the system to meet subsidence conditions. The inhibiting effect on surface development of mineral workings had led to the avoidance of tall blocks which were so susceptible to the ground movements, tilts and strains of the subsidence wave. The jacking method (combined possibly with automatic control) to counter long term subsidence movements might provide a means of bringing variety in mining area surface development, without impeding the extraction of minerals.

146. Having become accustomed during the project to the use of pre-stressing in the floor system, it was difficult to remember back to the advantages that prestressing offered compared with reinforced concrete, which presumably would have been less costly on current cost trends. Would Mr Adler always use prestressed concrete floor systems on future jack-blocks?

147. The main omission in the Paper was information on costs which was perhaps not surprising. As the first building ever built in this system, cost information on it would possibly be as relevant as information on the cost of a prototype motor car or a new ballistic missile. The economic viability of the system was, however, of some interest and since the structural component would to all appearances be more expensive than that of a conventional building, the return for this increased cost by way of savings in the cycle of following and finishing trades must have been assessed as being substantial. Some indication of the cost advantages might prevent the reader making misleading deductions from the critical path cycles shown in Fig. 13.

148. The limiting forms and sizes of the jack-block structures must have been evaluated and some mention of these factors would be helpful. It was difficult to conceive that the method must be limited to load-bearing core and cantilever floor 
construction and its development to other structural forms must have been studied. Further, what were $(a)$ the minimum number of storeys at which the system became competitive and $(b)$ the maximum number of storeys that could be contemplated for construction at present?

149. Mr Adler was to be congratulated on his excellent Paper and he and his colleagues could take a justifiable pride in the notable building which had been evolved from an imaginative engineering concept to which had been applied the most praiseworthy engineering techniques and ingenuity.

The Author in reply said that one point which continually arose was the question of cost. He could confirm that it was very easy to design a jig, a jacking system, a prestressed cantilever floor, etc, or to calculate any number of stress diagrams, but when it came to the question of assessing the cost, this was a totally different matter!

151. He wished to take the opportunity to thank Mr Hirschman and Dr Brown of his office for their assistance with regard to the preparation of the Paper and the various slides he had shown. He also wished to mention that $\mathrm{Mr}$ Reith, who contributed to the discussion, was Site Agent and, for quite a considerable time, was in the Author's office in a senior capacity assisting in the design of the jack-block. Thanks were due to him.

152. Mr Bidgood had given interesting illustrations of his lift slab system, and the Author fully agreed with all the points he made and was grateful that he did not ask any questions!

153. Mr Rose asked about the proportion of labour saving. This was rather difficult to quote in terms of actual figures, but it was established that there was a considerable labour saving, even in Coventry, which was the prototype. There were many dry-finish systems of partitions and cladding on the market and all of them could be used, but these were not an essential element of the jack-block principle. It did not follow that because the structure was erected in reverse the same procedure had to be followed for the finishes.

154. The accuracy in vertical alignment of the lift shaft was at least as good as in a conventional structure and was well within the tolerances specified by the lift manufacturers. He felt they had done the right thing when they decided to test rather than attempt to calculate the ultimate strength of the dry-jointed stacks of blocks.

155. The tests were very straightforward: the blocks were stacked one on top of the other and loaded to failure in a 1000-ton testing machine. It was wiser to adopt this simple procedure than to base the design on a lot of probably complicated and possibly fallacious calculations. How, for instance, were the inaccuracies to be accounted for in such calculations? It was shown by the tests that the ultimate load of the stacks was about $30 \%$ less than the value based on the cube strength, which was rather better than anticipated. It would have been difficult to arrive at this figure by calculation.

156. He was impressed with Mr Rose's suggestion about using two towers to lift complete apartments in boxes. This was a good method, and probably fast too, but he felt that large buildings would be required to justify this method. He had in mind the one mile high tower of Frank Lloyd Wright in this connexion!

157. Mr Hansen's methods of erecting bridges were fascinating. His approach to the problem of controlling loads by using hydraulic jacking equipment was in accordance with the Author's own views on this subject, and he was happy that Mr Hansen had justified this method of control. It was general knowledge that the Americans, Russians, and French had all moved brick buildings on rails right through their cities, and perhaps this knowledge gave him the required audacity to move buildings in the vertical direction.

158. In reply to Mr Hughes, he wished to say that as far as the one weekly cycle was concerned, as suggested in the Paper, there was no great difficulty in having higher stacks of blocks free standing. They had since tested stacks of nine blocks 
and had found their load-bearing capacity was of the same order. It was established that up to the conventional buckling dimensions the number of blocks in a stack did not influence the bearing capacity. The factor which limited the height of the stacks tested was the height of the press.

159. He agreed with $\mathrm{Mr}$ Wimborne that it was a great problem to plan buildings ahead, especially when building on the scale of the Millbank development, and he felt that somehow it was easier to plan ahead buildings which were to be constructed for repetition. It might well be very difficult to plan the prototype but once the teething troubles had been overcome, most of the problems of planning would then no longer exist.

160. Mr Mitchell and Mr Jenkins wondered how the cantilever construction of the building compared with beam and slab construction. The cantilever construction was doubtlessly more expensive than the beam and slab construction. However, the cantilever produced on a jig was very much cheaper than any cantilever built in a conventional way. The mass production of cantilevers on a pretensioning bed was not totally unreasonable as far as cost was concerned. It was important to remember the choice which confronted them in the early stages of design. This was whether to go for an economical structure and accept the resulting complications and cost in the jacking equipment and procedure, or whether to go for a structure which, although undoubtedly more expensive, possessed the all-important property of reducing to a minimum the number of unknowns in the relatively untried and much more difficult problem of jacking. It was basically a matter of deciding which of the two problems, structural or hydraulic, should receive priority. The choice was made in favour of the latter, since it was in this field that the real problems were likely to arise and where little help from past experience would be available for their solution.

161. They had wanted a symmetrical layout and an infinitely stiff structure, so that the control of the jacking procedure would be as simple as possible and the possibility of damage to finishes would be reduced to a minimum. It was such considerations which influenced the design and it was felt that this attitude was justified. The cantilever construction was chosen for the prototype as a simplifying expedient and not as a structural necessity or an architectural requirement.

162. With regard to Mr Findlay's remarks, it was the Author's feeling that in the course of development and especially in the development of equipment, one would eventually arrive at methods of jacking similar to the well-developed American techniques based on the method of control employed in lift slab, and he could envisage economical 8 to 10 storey structures erected by the jack-block technique, in which individual columns were jacked instead of core walls.

163. The introduction of column jacking would lead to a flexibility equal to that possible in conventional building construction which would represent a considerable advantage over accepted methods of industrialized building where the use of prefabricated components must necessarily impose limitations on flexibility of plan, elevation and material. It was in this respect that the difference between 'jigging' and prefabrication became significant.

164. The use of high-alumina cement for the infills between stacks of blocks was confined to the few cases where a saving in overall construction time would result. These infills acted as shear connectors but were not load bearing. No overheating was expected and none was observed, since the infills were 4 in. wide between cold concrete faces. He agreed with Mr Smollet's comments on the problems arising from the country's shortage of designers of the right calibre. He felt that such ventures stimulated interest in civil engineering and in the long run lead to an increase in the number of entries into the profession. This would result in a gain and not a loss in the country's brain power.

165. There had been no difficulty with the lift manufacturers. They were quite happy to erect their rails upside down.

166. Mr Benjamin's queries concerning secondary structural effects had already 
been answered to some extent. Plaster was used in the finishes and little cracking had occurred, none of which could be attributed to the jacking operation.

167. Measures were taken to ensure that no relative movement took place between the ends of the cantilevers. Struts were placed vertically between the cantilever ends and the upward deflexion of the cantilevers under prestress was used to induce the required compression in the struts.

168. Normal pre-cast concrete planks with in situ topping were used for the floors. These had shown no signs of distress and indeed there was no reason why they should.

169. The time interval between parking the building and its readiness for occupation was of the order of two and a half months.

170. Mr Rayman had raised the question of the application of the jackblock technique in mining subsidence areas. Very few additional developments would be required for its application in this context, although the suggestion of automatic control was a rather intriguing idea.

171. As had already been pointed out, the method did not automatically imply the use of cantilever floors, where prestressing obviously offered considerable advantages, and the decision as to whether pre-stressing would be used in future would be made on the basis of the structural system adopted.

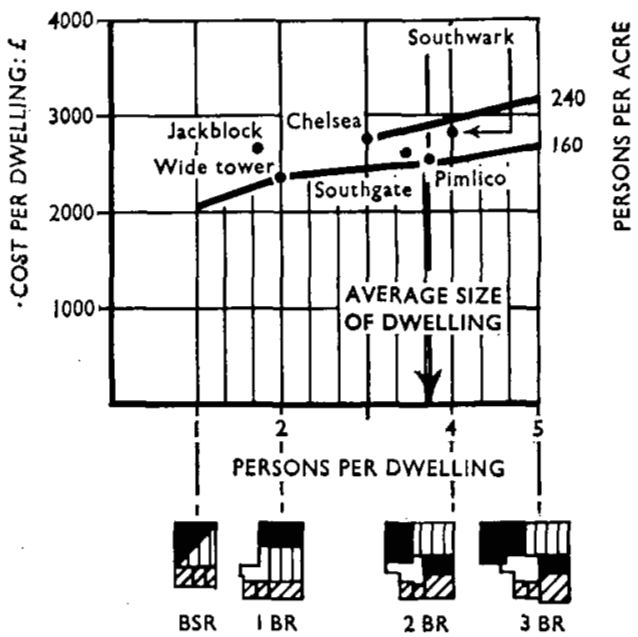

FIG. 41 : CONTRACT PRICES FOR MULTI-STOREY BUILDINGS

172. Referring once more to the question of cost, some estimate could be obtained from Fig. 41 which showed the contract prices for multi-storey buildings as published by the Ministry of Housing and Local Government. It could be seen that the jackblock contract price compared favourably with that for other conventional buildings of the same height. The cost of the prototype exceeded the contract price, but in order to determine what proportion of the actual cost could be attributed to development work and to teething troubles, a quantity surveyor had been employed on site for the duration of the contract with the aim of producing a realistic cost analysis. It was encouraging to learn that this analysis showed that in future jobs, and particularly in contracts which allowed repetition, there should be no difficulty in achieving the contract price.

\section{REFERENCE}

1. Neville A. M. A study of deterioration of structural concrete made with high-alumina cement. Proc. Instn civ. Engrs, 25, (July) 1963, 287-324. 